\title{
De Mujeres y Músicas Transatlánticas en el Universo Narrativo de Maryse Condé
}

\author{
Martha Asunción Alonso \\ Universidad Complutense de Madrid
}

Resumen: El presente artículo propone un acercamiento crítico, en clave musical, a la obra narrativa de la escritora antillana Maryse Condé (Guadalupe, 1937). Más concretamente, nuestro objetivo es analizar las implicaciones narratológicas de las diversas referencias musicales que pueblan los grandes títulos de Condé: Histoire de la Femme Cannibale (2003), Victoire... Les Saveurs et les Mots (2006), La Vie Scélérate (1987), La Belle Créole (2001), Desirada (1997), En Attendant la Montée des Eaux (2010). Trataremos de ver en qué medida esas alusiones se constituyen en elementos capitales de una cierta poética transatlántica que, basada en la voluntad de abolición de las orillas y fronteras, configura el arquetipo de heroína típicamente condeana.

Palabras claves: Atlántico, Caribe, Antillas, narrativa, mujer, músicas, Maryse Condé

Résumé: Cet article propose une approche, d'un point de vue musicale, de l'œuvre narrative de l'écrivaine antillaise Maryse Condé (Guadeloupe, 1937). Plus concrètement, nous nous proposons d'y analyser les implications narratologiques des allusions musicales qu'il est possible de repérer, un grand nombre, dans les grands ouvrages condéens: Histoire de la Femme Cannibale (2003), Victoire... Les Saveurs et les Mots (2006), La Vie Scélérate (1987), La Belle Créole (2001), Desirada (1997), En Attendant la Montée des Eaux (2010). Nous tenterons de voir à quel point ces références véhiculent une poétique transatlantique visant l'abolition des frontières: une poétique au cœur même de la construction des héroïnes typiquement condéennes.

Mots-clés: Atlantique, Caraïbe, Antilles, narrative, femme, musiques, Maryse Condé 
La extensa obra narrativa ${ }^{1}$ de la escritora antillana Maryse Condé (Pointe-à-Pitre, Guadalupe, 1937), acreedora en octubre de 2018 del denominado "Premio Nobel alternativo de Literatura", ${ }^{2}$ se encuentra poblada por personajes femeninos de inagotable resiliencia. En su inmensa mayoría, se trata de heroínas africanas o antillanas que han sufrido y combatido múltiples violencias patriarcales en sus trayectos vitales, todos ellos íntimamente ligados a la experiencia traumática y definitoria en lo que a la identidad respecta, como veremos, del viaje - o, mejor dicho, del pasaje - transatlántico.

De ahí que nos permitamos aquí bautizarlas como "mujeres transatlánticas", esto es, sujetos literarios definidos primeramente por su accidentado tránsito a través del vasto espacio del océano Atlántico - en su sentido tanto literal o físico como literario o simbólico y metafórico. Un tránsito este que viene a transformarlas, de algún modo, en arquetipos de una cierta identidad híbrida, nómada, apátrida y abierta; una identidad construida a golpe de voluntad y de contactos con la otredad en todas sus formas; una "identidad-mundo", por así decirlo, que amalgama plurales facetas translingüísticas y transculturales (vide Moura / Porra 2015).

Nuestras ideas de "mujeres transatlánticas", definidas por su "identidad-mundo", como se ve, heredan de la noción de "littérature-monde" expuesta en el célebre manifiesto homónimo que en su día firmaron en la prensa francesa (en Le Monde) el 16 de marzo de 2007,3 un grupo de escritores e intelectuales de la francofonía. Entre sus filas se contaban haitianos, como Dany Laferrière; o antillanos, como la guadalupeña Gisèle Pineau o, sería imposible no subrayarlo, el martiniqués Édouard Glissant. Los esfuerzos teóricos y creativos de este último por acotar las implicaciones de la creolidad o "créolité" y la antillanidad o "antillanité" (vide Bernabé / Chamoiseau / Confiant 1993) orbitan, precisamente, en torno a la abolición de la etiqueta de "francofonía", reductora y cargada de jerárquicas connotaciones (post)colonialistas.

"Le centre", podíamos leer en aquel utópico manifiesto, "n'est plus le centre". La metrópolis y su canon literario igualador en el peor sentido (fabricante de homogeneidad artificial, domesticada, forzada) habían dejado, según los firmantes, de ser el vórtice o la cúspide de la pirámide de la legitimización cultural. "Le centre" se instalaba, al fin, "aux 
quatre coins du monde", incluyendo las otras orillas transatlánticas y su rosario de archipiélagos. Pues la posibilidad del meridiano (vide Porra 2008) y la pirámide misma, en la óptica del manifiesto, habían dejado de existir.

Sin entrar en esta ocasión en consideraciones sobre la dimensión utópica y el trasfondo político de aquel texto, diremos que la autora que hoy nos ocupa, Maryse Condé, se sumó a la lista de intelectuales que lo secundaron en su segunda etapa. Es decir, cuando el manifiesto se retrabajó y publicó posteriormente como un volumen de artículos sobre la misma temática y con el mismo título en la casa parisina Gallimard. Figuran en la antología prólogos de los editores, Jean Rouaud y Michel le Birs; una entrevista con Glissant y ensayos breves de notables escritores francófonos.

No sorprende, pues, que las heroínas condeanas testimonien con sus dinámicas transatlánticas de ese desplazamiento del epicentro canónico a las periferias. Un desplazamiento que, en realidad, supone más bien una descentralización en toda regla y la alteración total del orden clásico unidireccional metrópolis-colonias, esto es, centroperiferias: Francia-Antillas.

En mitad de tan problemático binomio, se extiende, instalado en el peso de los siglos, el océano Atlántico. En la narrativa de Maryse Condé, desempeña un papel simbólico capital, en tanto que elemento adyuvante al "déplacement subjectif des éléments intégrant les identités des personnages" (Moura / Porra 2015: 93). El resultado narratológico, así las cosas, "est du côté de l'ouverture identitaire" (ibidem).

Esta apertura identitaria de las heroínas transatlánticas condeanas se produce, primordialmente, a través de la música, elemento que permite la sublimación de sus respectivas experiencias del dolor. Pues la vivencia del sufrimiento, bajo bien variadas formas, se encuentra en el origen del imperioso impulso creativo que sienten muchas de estas mujeres condeanas, a quienes en nuestra tesis doctoral bautizamos como "mujeres caníbales" (Alonso 2018).

Por "mujeres caníbales" entendemos referirnos al arquetipo de personaje femenino transgresor e inconveniente en tanto en cuanto su devenir creador, sus inquietudes artístico-intelectuales y la iniciativa de dinámicas sociales contradicen las actitudes de 
pasividad, los estereotipos de dependencia y el semantismo de domesticidad clásicamente atribuidos a la mujer en nuestras sociedades patriarcales.

Se trata de mujeres que, en lugar de esperar ser metafóricamente (o literalmente) devoradas por un universo inhóspito a lo femenino, dan el paso de devorar en legítima defensa. Por ejemplo, creadoras (de letras, de imágenes, de músicas...) en ambientes donde la producción artística parece territorio vedado al denominado "sexo débil" y monopolio masculino. Personajes que desafían los supuestos dictados biológicos de la maternidad, el mito del instinto, la trampa del amor romántico o los tabúes del deseo en femenino. Mujeres que redefinen la femineidad desde sus individuales diferencias, desafiantes, rebeldes, inclasificables en los corsés de ningún prototipo. Mujeres, en fin, productoras, ante todo, más que meramente re-productoras.

Tomamos como inspiración para bautizar este hallazgo la novela condeana de 2003 Histoire de la Femme Cannibale, protagonizada por Rosélie, antillana exiliada en Sudáfrica que, en un momento dado, inspirada por el suceso real de una mujer maltratada que terminó despiezando y devorando a su esposo, toma la senda de su emancipación y su realización como individuo y como artista. Devora, simbólicamente, al esposo opresor para hacer escuchar, por fin, su voz libre.

A este respecto, la propia Maryse Condé cita, como origen teórico de este fenómeno de la "mujer caníbal" el texto Manifesto Antropófago (1924) de Oswald de Andrade (18901954). Pone además en paralelo el movimiento de canibalización de la mujer oprimida hacia el hombre opresor y la canibalización necesaria del colono por parte del colonizado: "Oswald de Andrade proposait au colonisé une solution lumineuse, une manière unique de résoudre le problème de la créativité et de vivre en paix avec ses multiples influences" (Condé 2015: 241).

La necesidad de metabolización del dolor conduce a estas heroínas de Maryse Condé a explorar los caminos del mundo y surcar el océano. Se trata de personajes nómadas o apátridas, siempre en ruta, ya sea por la herida oculta que les supuso la trata esclavista de sus antepasados o bien por ser migrantes contemporáneas, de todas las extracciones sociales posibles. La necesidad de metabolizar artísticamente ese dolor les conduce también 
a explorar las sendas de la escritura; así como otros derroteros creativos: las artes plásticas, las artes culinarias y la música. El pasaje físico del Atlántico se perfila, pues, como símbolo de esa metabolización creativa de lo vivido.

No resulta sencillo trazar una férrea línea divisoria entre los diferentes perfiles de personajes femeninos creadores-transatlánticos en la obra de esta gran figura de las letras guadalupeñas. A decir verdad, desde la óptica condeana criolla, todas las formas de creación y, por ende, todas las mujeres creadoras estarían íntimamente ligadas. Destaca especialmente la asociación entre literatura y música: “Un écrivain c'est du sens, mais c'est aussi du son! Tout écrivain écrit une partition musicale" (Condé apud Pfaff 2016: 69).

De esta cita puede desprenderse la idea de que la literatura, para Condé, tiene más que ver con lo genuino y lo innato de los ritmos populares periféricos que con los academicismos tradicionalmente asociados a la imagen del autor varón, paladín de la lectoescritura elitista y asociado a la idea del centro canónico europeo. La escritura y, por extensión, la escritura en femenino se encuentran hondamente conectadas con la musicalidad, las otras orillas y el comentado tránsito creativo entre todas ellas.

Queremos, por ello, centrarnos a lo largo de estas páginas en las mujeres de letras condeanas entendidas en el sentido menos escolar, metropolitanos y canónico posible: en un sentido tan rítmico como libre.

Trataremos, así, de las mujeres negras de esas otras orillas, de las contadoras/cantadoras expertas que pueblan la vasta bibliografía de Condé. Mujeres contadoras/cantadoras, por cierto, más por herencia y genealogía que por formación o escolarización; $y$, en ese sentido, mujeres guerrilleras de un cierto contra-poder transatlántico (Rosemain 1986: 87-97): “C'est que ma mère aussi fait partie des musiciens. Elle chante. Comme sa mère avant elle et la mère de sa mère et la mère de sa grand-mère. C’est comme cela de toute l'éternité" (Condé 1997: 209).

Mujeres que, independientemente de su nivel de alfabetización a la manera metropolitana-occidental, dominan el lenguaje universal del compás y la emoción. La belleza que hermana. Mujeres poetas y músicas innatas, auditivas e intuitivas. Mujeres que, 
retomando la lúcida terminología del intelectual senegalés Léopold Sédar Senghor, son “poètes gymniques" (Senghor 1990: 161).

El propio Senghor, en el postfacio que hubo de escribir tras las reacciones cuanto menos ambiguas que generó su Anthologie de la Nouvelle Poésie Nègre et Malgache (1948), obra capital de la Negritud, menciona un ejemplo de esta categoría de mujeres productoras de música-poesía, relegadas al margen más invisible de la historiografía literaria canónica (escrita) para la posteridad:

Marône, la poétesse de mon village [...]. J’ai découvert le génie de Marône au cours d'une enquête que j'effectuais sur la poésie négro-africaine de tradition orale. Auteur de quelque 2000 chants gymniques, elle avait étendu sa gloire aux limites de l'ancien Royaume de Sine (Sénégal). (idem: 167)

Las heroínas africanas y antillanas de Maryse Condé bien podrían provenir de esa Marône real rehabilitada por Senghor, de una de las muchas Marône sin duda existentes en el África Negra y los espacios créoles caribeños. Hablamos, en suma, de mujeres portadoras del compendio de saberes literarios y musicales, genuinamente femeninos, que los autores caribeños Jean Bernabé, Patrick Chamoiseau y Raphaël Confiant definieran, bien lo sabemos, como oralitura (Bernabé et alii 1993: 153-171). Mujeres cuyas voces transitan por los espacios, visibles e invisibles, de esa "petite magie" inconfundible de la atmósfera antillana (Monnerot apud Ega 1989: 9). Mujeres “maîtres de la parole" (Condé 2001: 88) y paradójicamente herederas de "la parole poétique de nos bardes" (Condé 1997: 210); de la magia del "griot et du troubadour, mais griot sans généalogie, rhapsode sans épopée, troubadour sans château fort, qui ressemble en sa performance nocturne un condensé de tous les arts du corps" (Maximin 2006: 18).

Partamos de las nueve funciones de la música según el etnomusicólogo y antropólogo cultural estadounidense Alan Merriam (1923-1980), que extendió sus investigaciones desde la Montana donde nació a muy diferentes y recónditas regiones transatlánticas africanas. Los usos y las funciones de la música, para Merriam, bien podrían aplicarse a las canciones, estribillos, ritmos y músicas de otras orillas (de ambas orillas: transatlánticas), en fin, de las que trataremos a continuación. Relacionadas de forma más o 
menos directa con las experiencias feminizadas del amor y su contrapartida, el desamor, estas funciones vehiculan en sí mismas sus contrarios, en nuestra opinión. Es decir, construyen y albergan igualmente, por oposición e in absentia, espacios de rebelión: donde exista el poder, parafraseando a Michel Foucault, existirá sin excepción posible resistencia y contrapoder en potencia (Foucault 1976: 125).

Merriam considera la música en tanto que conducta humana por definición y que nos define: conducta, en definitiva, de alcance universal. Sin la música, el hombre no podría llamarse hombre. Nosotras añadimos que la mujer no podría, sin música, llamarse mujer; ni la música podría recibir tal nombre sin la mujer. No en vano el género del término, gramaticalmente hablando, es femenino. Como bien señala Jesús Aranda Camuñas (2014), proviene etimológica y mitológicamente del griego "mousiké”. Este término contiene una atávica referencia a las nueve hermanas mujeres de Júpiter, padre de los dioses olímpicos de la Antigüedad. Nos referimos, claro está, a las consabidas y caprichosas musas, indispensables en el Panteón politeísta griego. De estas madres de la música, como es lógico, nacerían en los siglos sucesivos dignas hijas, que vendrían a enriquecer la tradición simbólico-narrativa occidental en sus referencias musicales:

Precisamente, la patrona de la música es una mujer, Santa Cecilia. Cada 22 de noviembre se conmemora en todo el mundo el Día de la Música en recuerdo a esta santa que murió un 22 de noviembre alrededor del año 180. Perseguida por las autoridades del Imperio Romano debido a sus creencias cristianas, Cecilia fue arrestada, y cuenta la leyenda que cuando estaba a punto de ser ejecutada, entonó un canto como alabanza a Dios. (Camuñas 2014: 5)

Las funciones de la música - mujer, pues, por naturaleza y definición, independientemente de los silencios en las páginas de créditos de la Historia -, son: (1) el goce estético, (2) el entretenimiento, (3) la comunicación, (4) la representación simbólica, (5) la respuesta física, (6) el refuerzo de la conformidad a las normas sociales, (7) el refuerzo de instituciones sociales y ritos religiosos, (8) la contribución a la continuidad y a la estabilidad de una cierta cultura, (9) la contribución a la integración de la sociedad (Merriam 2001). 
La realización de todas estas funciones (en ocasiones, mediante la subversión de sus fines), como trataremos de ver a continuación, subyace tras los ecos constantes de músicas latinas que, asociadas a lo femenino, se escuchan en las novelas de Condé.

Observemos, por ejemplo, el personaje de la guadalupeña Rosélie en la novela Histoire de la Femme Cannibale (2003). Rosélie ha cruzado el Atlántico en busca de la madre África y se instala, con su dolor a cuestas, en Sudáfrica. Ha deshecho, rehaciéndolo, la herida infligida por el terrorífico Middle Passage de los esclavos africanos capturados para ser vendidos en las Antillas. Rosélie alberga vocación de artista plástica: pintora. Creadora que, durante años, sufrirá en primera persona el fenómeno que la escritora española María Teresa León, compañera del poeta gaditano Rafael Alberti, bautizara en sus memorias para referirse a sí misma: a su propia vida de intelectual eclipsada tras el reconocimiento social al esposo - como "la cola del cometa” o las “mujeres-sombras” (León 1970: 241, 310). Rosélie es, por añadidura, una gran melómana. No podía ser de otra forma. Su nombre de pila resulta de la fusión de los nombres de sus padres: Rose y Élie. Ambos se nos describen como grandes escuchantes y, lo que es más importante, dotados también para la creación musical. De tal palo, como sabiamente reza el refranero español, tal astilla.

De la madre, la obesa Rose, sabemos que poseía una voz "de sirène mezzo-soprano" y sabemos que

avec du métier, elle aurait pu devenir cantatrice professionnelle. Elle lui avait susurré [à Élie] à l'oreille l'air bien connu de Carmen [(Callas 1964)], elle n'appréciait que les mélodies françaises, pas les créoles, trop vulgaires, parfois les espagnoles:

L'amour est enfant de Bohême

Il n'a jamais, jamais connu de loi,

[...]. (Condé 2003: 16; vide Condé 2006: 87, 199, 230, 262, 277)

La noción misma de orilla y toda distancia parecen quedar abolidas en la paradoja que sostiene a estos personajes: mujeres antillanas que, en contra de cualquier cliché, escogen como himno ritmos lejanos, extranjeros, exóticos, venidos del otro confín del 
océano.

El Amor es un Pájaro Rebelde, aria para mezzosoprano mítica de la ópera del francés Geoges Bizet (1875), más conocida por la denominación popular "La Habanera”, constituye, de hecho, un leitmotiv que recorre toda la narrativa condeana. La recurrencia en las historias de Condé de este estribillo podría autorizarnos a hablar, incluso, de obsesión musical. ¿A qué otros mecanismos poéticos podría responder esta fijación? Tratemos de ver un poco más claro los posibles elementos de respuesta a esta cuestión.

Recordemos brevemente la dramaturgia musical de Bizet. La habanera L'Amour est un Oiseau Rebelle era entonada por el personaje de la gitana Carmen, hermosa cigarrera española de carácter explosivo y sensual. Carmen se identifica con el estereotipo que, según el imaginario francés, le corresponde a todo elemento relacionado con el universo hispano y, muy en especial, con la etnia gitana. La periferia y la diáspora, una vez más.

Carmen representa el vitalismo, lo femenino, lo dionisíaco, lo meteco y llegado de regiones ignotas; frente al racionalismo apolíneo, la virilidad, el centralismo y el canon que vehicula el personaje masculino de Don José. Carmen representa, en suma, la orilla marginada y el "amor-pasión" que, retomando a Denis de Rougemont, “apareció en Occidente como una de las repercusiones del cristianismo [...] en las almas en que aún vivía un paganismo natural o heredado" (Rougemont 1978: 76). Podemos, así las cosas, tomar este símbolo musical en la narrativa condeana como oda a la descentralización y también como "exaltación del amor desgraciado" (idem: 77), de lo funesto que augura dicho amorpasión de raíces tan paganas como occidentalizadas: créoles en esencia.

¿Podría, además, interpretarse este leitmotiv musical en la obra de Condé en clave de amor mixto? Estaríamos ante una nueva problematización, en segundo grado, de una realidad ya de por sí compleja, capital de la narrativa condeana: las relaciones amorosas, en primera instancia; y las relaciones amorosas entre individuos con diferentes orígenes étnico-culturales y diferentes colores de piel, en última instancia. Individuos que unen, al unirse ellos mismos, realidades clásicamente irreconciliables y subordinadas: los dos polos al fin iguales de un Atlántico que queda, así, reducido a una suerte de "mare nostrum" oceánico (Moura / Porra 2015: 61). 
La banda sonora de los recuerdos maternos y los retratos femeninos condeanos tanto en sus obras explícitamente autobiográficas como en el resto - pasa, además, por otras habaneras, boleros, swings y melodías célebres de la música romántica en lenguas latinas (preferentemente, en español; pero también, aunque en menor medida, en italiano o francés).

Citaremos, para ilustrar este punto, la canción "Bésame, bésame mucho, / Como si fuera esta noche / La última vez" (King Cole 1991; Condé 2003: 86); los estribillos "Amado mío, / Donne tes lèvres..." (Les soeurs Étienne 2011; Condé 1987: 122; Condé 1993: 114), $O$ sole Mio de Mario Lanza (Condé 1997: 88), "Cherubino. Voi che sapete che cosa è amor" (Condé 1997: 256); las melodías de "Francis Cabrel" (Condé 2010: 275), "Piaff" o "Brassens" (Condé 2008: 223); los "payadores" 4 chilenos (Condé 2008: 220), “Quisas, quisas..." (Condé 2010: 307) o las bandas sonoras de exitosas películas italianas:

Il l'avait emmenée voir des Films de Tino Rossi qu'elle adorait et dont elle chantait les succès:

Marinella, oh reste encore dans mes bras,

avec toi, je veux jusqu'au jour

chanter cette chanson d'amour. (Condé 2003: 179, 180)

La música, de apasionado acento latino, resulta innegablemente femenina. Y, como sugieren las ideas más socialmente arraigadas de la feminidad, innata. La analfabeta abuela de la autora manifestará por ello una inclinación natural a la música, además del don de la cocina. Se (re)ivindica en Victoire... el genio artístico de una iletrada Victoire Quidal, no sólo como artista de los fogones: Condé insiste en la exquisita sensibilidad musical de su ancestra guadalupeña, además de en su sentido del ritmo y su oído privilegiados, patentes desde su más tierna infancia:

Dès que la musique s'éleva, Victoire s'approcha de l'appareil à le toucher. Elle resta clouée en place, fascinée par la lente rotation de l'aiguille. Quand la mélodie s'arrêta, elle se mit à piétiner, elle si douce: - Mizik! Mizik! (Condé 2006: 37) 
La universalidad del lenguaje musical resulta así capaz de abolir todas las fronteras, orillas y diferencias existentes entre seres humanos, por hondas que sean, visibilizando los lazos de la fraternidad y, en el caso de Victoire, la sororidad o fraternidad feminista entre mujeres. La música la unirá a Anne-Marie Walberg, personaje miembro de una casta racial y social en todo opuesta a su universo de servidumbre negra:

- Tu aimes ma musique? avait-elle interrogé, étonnée.

- Oui, mamzel! - avait soufflé Victoire.

$[\cdots]$

Ainsi naquit une relation, mystérieuse et solide, qui devait en exaspérer et faire jaser plus d'un. (idem: 82)

Por antítesis, los personajes masculinos no suelen manifestar, salvo notables excepciones (como el músico Gesner, en La Vie Scélérate, 1987), estos talentos innatos y vocaciones musicales. Del padre de Rosélie, el mujeriego Élie, apenas si conocemos en Histoire de la Femme Cannibale su amor por la música afro-cubana y latina, también mencionada en La Belle Créole (Condé 2001: 132), en Desirada ("La Cumparsita", Condé 1997: 272); en La Colonie... (“La Cumparsita. Adiós pampa mía”, Condé 1993: 114; “... de vieux airs de tangos argentins dans les rumbeadores...", Condé 1993: 139), en Les Belles Ténébreuses ("Por el camino del sitio mío / un carretero alegre pasó", Condé 2008: 73), en Hugo le Terrible (Condé 1991: 87, ss.), en Savannah Blues ("salsa”, Condé 2009: 55, ss.) o en En Attendant la Montée des Eaux (“merengues", Condé 2010: 168, ss.).

Guantanamera, ${ }^{5}$ Dos gardenias et Tutti quanti. Dans son Jeune temps, Élie avait même embouché une clarinette [...]. Il avait formé un groupe: les Musical Brothers. L'ensemble s'était fait un petit nom en animant les bals titane ou les bals à quadrille. (Condé 1987: 130)

No sorprende demasiado que la hija de los melómanos Rose y Élie herede la melomanía de los progenitores. Durante sus años en Ciudad del Cabo (Sudáfrica), el personaje de Rosélie hará de la tienda de discos de Mme Hillster su reino. La boutique en 
cuestión recibe el nombre de Three Penny Opera y su descripción suena a los más variados ritmos:

Tout voisinait avec tout dans le plus grand désordre: les chants de Noël avec les requiem, les motets avec les oratorios, les suites pour violoncelle avec les airs de raï, Cesaria Evora ${ }^{6}$ avec Cheb Mami [...]. ${ }^{7}$ Un autre jour, Rosélie s'était trouvé nez à nez avec le disque d'or de Salama Salama [...]. Le Reggae des Damnés. (Ibidem)

La descripción de la tienda de discos Three Penny Opera, en Histoire de la Femme Cannibale (2003), suena, en resumen, a la polifonía y la mixtura rítmicas propias de la narrativa condeana en sí, notable ejemplo de literatura-mundo. Hibridación, por añadidura, igualmente típica de las músicas latinas: modélica amalgama de influencias transatlánticas. Así las cosas, para iniciar la senda de las conclusiones, podemos decir que la música forma parte, en el universo condeano, de un cierto capital cultural femenino intangible, cuya transmisión oral se realiza de abuelas a madres, de madres a hijas, y así sucesivamente generación tras generación mediante el viaje y el contacto con ritmos de diferentes rincones del mundo, sin jerarquía entre ellos.

La función musical, según Merriam, de contribución a la estabilidad y continuidad a una cierta cultura-mundo de la apertura identitaria (9) queda, pues, completamente realizada. También la función 10 (la contribución a la integración de una sociedad), en tanto que la música se revela para estas heroínas como fundamento matrimonial (que no patrimonial) de una comunidad en femenino, hecha de lazos entre mujeres transatlánticas de todas las orillas.

Por otra parte, la sorprendente amistad que, gracias a las canciones e instrumentos, surge entre los personajes de la criada negra Victoire y la burguesa blanca Anne-Marie ilustra bien el valor simbólico-comunicativo y la potencialidad contestataria de la música, navío capaz de sortear las distancias más insondables.

En análogo sentido interpretamos las músicas que ambientan en las novelas de Condé el tratamiento de las pasiones mixtas o interraciales, o bien de las relaciones difíciles, 
en general: cantar puede, en efecto, ser un buen sinónimo de subvertir. Como lo es siempre el verbo amar, que sintetiza el viaje supremo hacia lo desconocido. El viaje hacia los otros.

Recordemos, para terminar, que Merriam observaba además el goce estético y la respuesta física entre las funcionalidades de la música. ¿Qué decir sobre este particular? Creemos que el disfrute de la rítmica prosa condeana, experiencia corporal donde las haya, sin duda terminará de convencer a los lectores que al cabo de estas páginas tengan la suerte de poder bailar-viajar por primera vez un texto de esta autora.

\section{NOTAS}

${ }^{1}$ Maryse Condé ha cultivado casi todos los géneros: desde el teatro a la novela, pasando por la autobiografía, los relatos y las narraciones juveniles e infantiles.

2 El origen de este Premio alternativo se remonta a mayo de 2018, cuando la Academia Sueca hizo pública su decisión de no entregar en aquel año el Nobel de Literatura.

${ }^{3}$ Fue firmado por los siguientes autores: Daeninckx, Ananda Devi, Alain Dugrand, Edouard Glissant, Jacques Godbout, Nancy Huston, Koffi Kwahulé, Dany Laferrière, Gilles Lapouge, Jean-Marie Laclavetine, Michel Layaz, Michel Le Bris, JMG Le Clézio, Yvon Le Men, Amin Maalouf, Alain Mabanckou, Anna Moï, Wajdi Mouawad, Nimrod, Wilfried N'Sondé, Esther Orner, Erik Orsenna, Benoît Peeters, Patrick Rambaud, Gisèle Pineau, JeanClaude Pirotte, Grégoire Polet, Patrick Reynal, Jean-Luc V.Raharimanana, Jean Rouaud, Boualem Sansal, Dai Sitje [sic], Brina Svit, Lyonel Trouillot, Anne Vallaeys, Jean Vautrin, André Velter, Gary Victor, Abdourahman A. Waberi. 
4 Trovadores rioplatenses y chilenos que improvisan a dúo, en verso, acompañados de una guitarra. La "payada" es, pues, una actuación de contrapunto: uno de los contrincantes responde, "payando", al otro. Pueden alargarse durante días. Pierde el payador que no responde inmediatamente.

${ }^{5}$ Machín, 1967. El famoso Dos Gardenias fue compuesto por una mujer, la pianista cubana Isolina Carrilo (1907-1996), mencionada por Condé en La Belle Créole (Condé 2001: 132).

${ }^{6}$ Gran cantante de morna, género musical propio de su país de origen, Cabo Verde (1941-2011). Se relaciona con los fados portugueses, pues Cabo Verde fue colonia lusa: ambos géneros se caracterizan por la nostalgia y se relacionan con el momento de los adioses. Evora, 2010.

${ }^{7}$ Gran cantante argelino de música raï (1966), que en 2009 fue condenado a dos años de cárcel en Francia por tentativa de aborto forzado a su pareja (S.A. (s/d), "Cheb Mami condamné à cinq ans de prison pour tentative d'avortement forcé", Le Monde / Reuters <http://www.lemonde.fr/societe/article/2009/07/03/cheb-mamicondamne-a-cinq-ans-de-prison-ferme_1214946_3224.html>, último acceso en 10/05/2019). El raï, cuyo nombre significaría "opinión" en árabe, surgió en Orán a inicios del siglo XX, como medio de denuncia. Se caracteriza, por tanto, por la irreverencia y provocación de las letras. 


\section{Bibliografía}

Alonso, Marta Asunción (2018), Negritud, Sororidad y Memoria: Poéticas y Políticas de la Diferencia en la Narrativa de Maryse Condé, Madrid, UCM. Tesis doctoral.

Andrade, Oswald de (1928), "Manifiesto Antropófago", Revista de Antropofagia, no 1, 3-7.

Bernabé, Jean / Patrick Chamoiseau / Raphaël Confiant (1993), Éloge de la Créolité, París, Éditions Gallimard.

Condé, Maryse (2015), Mets et Merveilles, París, Lattès.

-- (2010), En Attendant la Montée des Eaux, París, Lattès.

-- (2006), Victoire, les Saveurs et les Mots, París, Mercure de France.

-- (2003), Historie de la Femme Cannibale, París, Mercure de France.

-- (2001), La Belle Créole, París, Gallimard.

-- (1997), Desirada, París, Robert Laffont.

-- (1993), La Parole des Femmes, París, L'Harmattan.

-- (1987), La Vie Scélérate, París, Seghers.

Ega, Françoise (1966), Le Temps des Madras, París, Éditions Maritimes et d'Outremer.

Foucault, Michel (1976), La Volonté de Savoir, París, Gallimard.

León, María Teresa (1979), Memoria de la Melancolía, Buenos Aires, Losada.

Maximin, Daniel (2006), Les Fruits du Cyclone: Une Géopoétique de la Caraïbe, París, Seuil.

Merriam, Alan (2001), "Usos y Funciones de la Música”, in Las Culturas Musicales, Madrid, Editorial Trotta.

Moura, J. M. / V. Porra (éds.) (2015), L'Atlantique Littéraire: Perspectives Théoriques sur la 
Constitution d'un Espace Translinguistique, Hildesheim, Georg Olms Verlag AG.

Pfaff, Françoise (2016), Nouveaux Entretiens avec Maryse Condé, Écrivain et Térmoin de son Temps, París, Karthala.

-- (1996), Conversations with Maryse Condé, Nebraska, University of Nebraska Press.

Porra, Véronique (2008), «Et s’Il n’y Avait pas de 'Méridien Littéraire'... Pour une Relecture de la Relation Centre-Périphérie à la Lumière des Littératures Migrantes en France et au Québec», in Écriture Migrante / Migrant Writing, Hildesheim, Georg Olms Verlag, 49-68.

Rosemain, J. (1986), La Musique dans la Société Antillaise, 1635-1902, París, L'Harmattan.

Rougemont, Denis (1972), El Amor y Occidente, Barcelona, Kairós.

S.A. (2007), "Pour une Littérature-Monde en Français", Le Monde des Livres, 16 de marzo de 2007.

S.A. (s/d), "Cheb Mami condamné à cinq ans de prison pour tentative d'avortement forcé", Le Monde / Reuters <http://www.lemonde.fr/societe/article/2009/07/03/cheb-mamicondamne-a-cinq-ans-de-prison-ferme_1214946_3224.html> (último acceso en 10/05/2019).

Senghor, Léopold Sédar (1990), CEuvre Poétique, París, Éditions du Seuil.

-- (1948), Anthologie de la Nouvelle Poésie Nègre et Malgache, París, PUF.

Martha Asunción Alonso es Doctora en Filología Francesa por la Universidad Complutense de Madrid, traductora y poeta en lengua española. 